must produce evidence of having attended at a recognised medical school specified courses of lectures on medicine, surgery, midwifery, pathology (including pathological hiscology and bacteriology), pharmacology and therapeutics, forensic medicine and insanity, and public health; of having received systematic practical instruction in these cubjects; and of having performed operations on the dead body. In addition he must show that he has attended, since passing his second examination, the practice of medicine and surgery, demonstrations in the post-mortem room, clinical lectures on medicine and surgery and diseases of women, and of having served as clerk and dresser in the wards. He must also have obtained a cer- tificate of instruction and proficiency in the administration of anæsthetics, and have attended special classes in ophthalmology, in fevers, in lunacy, and in vaccination, and must have attended twenty labours. In addition be must be twenty-one years of age or older.

The examination is in three parts, medicine, surgery, and midwifery, and the student is allowed to take the third part at the completion of four years of medical study. The examination in each part comprises a paper of sis questions, four of which must be dealt with, and a viva voce. In surgery and medicine there are additional viva voces in anatomy and pathology, together with a long viva on "clinical cases."

\title{
THE FELLOWSHIP OF THE ROYAL COLLEGE OF SURGEONS.
}

The Fellowship of the Royal College of Surgeons of England is justly esteemed as the premier qualification that the student can obtain in surgery, and is almost an essential to anyone who aspires to the higher surgical posts in England. The student should decide early in his career whether he wishes to obtain the F.R.C.S. For this purpose it is necessary to pass two examinations, a primary and a final.

The Primary examination takes place twice every year, in May and in November, and is held in London. The subjects are Anatomy and Physiology, and candidates must have passed the second Conjoint examination or some other equivalent examination which exempts them from it. They must also (except in the case of members of the college) have spent three winter sessions or eighteen months in dissections and attendance at physiology classes at a recognised school. The fee for the examination is $£ 55 \mathrm{~s}$. The examination is partly oral and partly written. Two papers are set, one in physiology and one in anatomy, four questions being given with an allowance of three hours. The oral examinations are two, lasting twenty minutes each, in the two subjects. The examination has the reputation of being unusually stiff, but its difficulty should not frighten the student or practitioner of reasonable ability who is willing to pay special attention to the two subjects. A good, sound knowledge of anatomy and physiology is required, and if the candidate has beet diligent at his practical work in the dissecting room and laboratory, and has supplemented the knowledge there gained by reading, he stands a good chance of success.

The examination for the Final Fellowship takes place in May and November of each year, and consists of a writter paper, viva voce, clinical examinations, and operatire surgery. The fee for the examination is $£ 1212 \mathrm{~s}$., and candidates who are members of the college are admissible when they have been six years in practice or in the study of medicine. Other candidates must show that they ar graduates in medicine of recognised Universities of four years' standing, and have attended the surgical practice of a recognised hospital for one year after graduation. Special classes for the Final Fellowship examination are held at most of the London hospitals; and practitioners who intend to enter for it, and have lost touch to any extent with hospital surgical practice, would do well to attend a full course of instruction at one of the medical schools before competing.

\section{THE CAMBRIDGE UNIVERSITY COURSE.}

THe degrees of Bachelor of Medicine (M.B.) and Bachelor of Surgery (B.C.) at this University are only conferred after the entire course of study with examinations for both has been carried out. The B.C. is, therefore, in itself a complete and registrable qualification to practise, and is frequently so used. To obtain either of these degrees it is necessary to pass five years in the study of medicine after registration as a student, and to reside for three years at the University. The professional examinations are three in number. The first comprises physics, chemistry, and biology; like similar examinations elsewhere, it is divided into two parts, which may be passed separately. The second absorbs at least two years' work, and frequently more (see regulations). In the third, or Final, examination there are two parts : one consists of patho- logy, bacteriology, pharmacology, etc., and may be taken as soon as various courses of lectures and laboratory work in those subjects have been duly attended; the other includes medicine, surgery, and midwifery with gynæcology, and it may not be attempted until the completion of the scheme of medical study, which includes three years' attendance on the practice of a recognised hospital.

When the third examination has been completed the student may take the degree of B.C. at once, but for the M.B. he must prepare and submit a thesis on some subject in medicine, surgery, or midwifery, selected by himself.

For the degree of M.D. it is necessary to have been M.B. at least three years, and to submit a thesis on some subject in modicine (not in surgery) which is a definite research or contribution to the knowledge of its subject.

\section{OXFORD UNIVERSITY.}

AT Oxford University two degrees in medicine can be obtained, the B.M. and the D.M.; similarly in surgery there are two degrees, the B.Ch. and the M.Ch. No candidate is eligible for any of these degrees unless he is a graduate in Arts, that is to say, either an M.A. or a B.A. ; in which branch of the Arts that degree has been obtained is a matter of little moment. The usual course of the medical student who has passed Responsions is to work at the Preliminary Science examinations in physics, chemistry, and zoology and botany, which are likely to take him two years or thereabouts, and then to spend a further two years in study for the Final Honour School of physiology, in which he takes his degree of B.A. He next has to pass examinations in organic chemistry is 
relation to medicine and in human anatomy, after which he prepares himself for his second Professional examination, which comprises the subjects of materia medica and pharmacology, pathology, forensic medicine and hygiene, and the Final subjects of medicine, surgery, and midwifery. When the examinations in these subjects have been passed, the candidate may supplicate for and obtain the degree of B.M., B.Ch.

The degree of D.M. is granted to Bachelors of Medicine of the University who have entered their thirty-ninth term -it should be remembered that there are four terms in the official year-who have presented a dissertation on some medical subject that is approved by the Professors of the Faculty and Examiners for the degree of Bachelor of Medicine for the time being whose subjects are dealt with in it. The degree of M.Ch. is granted to Bachelors of Surgery of the University who have entered their twenty-seventh term and satisfied some other requirements; the examination for this degree is held annually in June.

\section{THE LONDON UNIVERSITY COURSE.}

The University confers the degrees of Bachelor of Medicine and Bachelor of Surgery (M.B., B.S.), Doctor of Medicine (M.D.), and Master of Surgery (M.S.).

The student who desires to take the degree of M.B. of the London University has to pass the University Matriculation Examination, held thrice yearly in January, September, and June. The matriculation is accepted as a preliminary examination for graduation or qualification in medicine, provided the candidate has taken Latin as one of the optional subjects, and formerly no other examination exempted from the matriculation so far as degrees of the University were concerned. Recently, however, the Senate has seen fit to rule that several other examinations may be accepted instead of the usual matriculation.

After matriculating the student must attach himself to one or other of the various medical schools, and devote himself during his first year to mastering the subjectschemistry, biology, and physics-required for his preliminary scientific or first professional examination. It will take him a full year to work up these subjects.

The student is at present admitted to the Intermediate examination, the subjects of which consist of anatomy, physiology, and pharmacology, two years after having passed Part I. of the Preliminary. Time spent in working at the subjects of anatomy and physiology is not recognised by the University until the student has passed the Preliminary. His second and third years are thus spent in work in the dissecting room and physiological laboratory.

Having passed his "Inter.," the student begins clinical work. Two years of clinical study were formerly required, but now three years will bo necessary, while two and a half years will be the minimum period required for the preliminary subjects. Thus the full course will in future occupy at least five and a half years from the time of matriculation.

The last examination is written, oral, and practical. The candidate is required to examine and report on selected cases, to do practical bacteriological work, and to be acquainted with the essentials of operative surgery, though actual operations on the dead subject are not demanded.

\section{HIGHER DIPLOMAS.}

The Royal College of Physicians of London grants its membership after examination to graduates in medicine of recognised Universities, or to licentiates of the College, being above the age of twenty-five years, who do not engage in trade, do not dispense medicine, and who do not practise in partnership. The examination, which is held in January, April, July, and October, is partly written and partly oral. The fee for the membership is $£ 42$, but if the candidate is a licentiate the fee is the difference between what he has already paid and $£ 42$. In either case $£ 66 \mathrm{~s}$. is paid before examination. The fellowship is elective.

The Royal College of Physicians of Edinburgh admits to its membership licentiates of the College, or of a British or Irish College of Physicians, or graduates in medicine of a British or Irish University over twenty-four years of age after examination in medicine and therapeutics and one or more of the following subjects selected by the candidate: (1) One or more departments of medicine specially professed, (2) psychological medicine, (3) general pathology and morbid anatomy, (4) medical jurisprudence, (5) public health, (6) midwifery, (7) diseases of women, (8) diseases of children, (9) tropical medicine. The fee to be paid by a licentiate is twenty guineas, by others thirty-five guineas. A member of three years' standing may be elected a Fellow. The fee is $£ 64$ 18s.

The Royal College of Surgeons of Edinburgh.-The Fellowship is granted, after examination, to any registered practitioner who is twenty-five years of age and has been in practice for two years. The examinations are written, oral, and practical. The fee is $£ 35$ to those who hold the diploma of licentiate of the College, and $£ 45$ to others (no stamp duty is payable on the diploma).

The Royal Faculty of Physicians and Surgeons of Glasgow.-Registered practitioners are admitted to the Fellowship by examination and by subsequent election. Four examinations are held annually (January, April, July, October). Fourteen days' notice must be given. The fee is $£ 30$ unless the candidate desires to qualify to hold office, when it is $£ 50$. In the case of a licentiate of the faculty, $£ 25$ and $£ 15$ respectively.

Royal College of Surgeons in Ireland Fellowship.(1) The examination for the Fellowship is divided into two parts-namely, the Primary and the Final. (2) The subjects of the Primary examination are anatomy (including dissections), physiology, and histology. The examination is partly written, partly viva voce, and partly practical. Candidates must pass in all the subjects at one examination. (3) The subjects of the Final examination are surgery (including surgical anatomy) and pathology. The examination is partly written and partly viva voce, and includes the examination of patients and the performance of operations on the dead body. Candidates must pass in all the subjects at one examination. (4) The examinations are held three times in each year. (5) Special examinations will not be granted by the Council under any circumstances. (6) Candidates are required to lodge their applications, certificates, and receipts for fees with the Registrar at least seven days before the date of the examiration. 